\title{
Thermal desorption of formamide and methylamine from graphite and amorphous water ice surfaces
}

\author{
H. Chaabouni, S. Diana, T. Nguyen, and F. Dulieu

\begin{abstract}
LERMA, Université de Cergy-Pontoise, Observatoire de Paris, PSL Research University, Sorbonne Université, UPMC Univ. Paris 06, UMR 8112, CNRS, 5 mail Gay Lussac, 95000 Cergy-Pontoise, France

e-mail: Henda.Chaabouni@u-cergy.fr, Francois.Dulieu@obspm.fr
\end{abstract}

Received 18 April 2017 / Accepted 27 December 2017

\begin{abstract}
Context. Formamide $\left(\mathrm{NH}_{2} \mathrm{CHO}\right)$ and methylamine $\left(\mathrm{CH}_{3} \mathrm{NH}_{2}\right)$ are known to be the most abundant amine-containing molecules in many astrophysical environments. The presence of these molecules in the gas phase may result from thermal desorption of interstellar ices.

Aims. The aim of this work is to determine the values of the desorption energies of formamide and methylamine from analogues of interstellar dust grain surfaces and to understand their interaction with water ice.

Methods. Temperature programmed desorption (TPD) experiments of formamide and methylamine ices were performed in the submonolayer and monolayer regimes on graphite (HOPG) and non-porous amorphous solid water (np-ASW) ice surfaces at temperatures 40-240 K. The desorption energy distributions of these two molecules were calculated from TPD measurements using a set of independent Polanyi-Wigner equations.

Results. The maximum of the desorption of formamide from both graphite and ASW ice surfaces occurs at $176 \mathrm{~K}$ after the desorption of $\mathrm{H}_{2} \mathrm{O}$ molecules, whereas the desorption profile of methylamine depends strongly on the substrate. Solid methylamine starts to desorb below $100 \mathrm{~K}$ from the graphite surface. Its desorption from the water ice surface occurs after $120 \mathrm{~K}$ and stops during the water ice sublimation around $150 \mathrm{~K}$. It continues to desorb from the graphite surface at temperatures higher than $160 \mathrm{~K}$.

Conclusions. More than $95 \%$ of solid $\mathrm{NH}_{2} \mathrm{CHO}$ diffuses through the np-ASW ice surface towards the graphitic substrate and is released into the gas phase with a desorption energy distribution $E_{\mathrm{des}}=7460-9380 \mathrm{~K}$, which is measured with the best-fit pre-exponential factor $A=10^{18} \mathrm{~s}^{-1}$. However, the desorption energy distribution of methylamine from the np-ASW ice surface $\left(E_{\mathrm{des}}=3850-8420 \mathrm{~K}\right)$ is measured with the best-fit pre-exponential factor $A=10^{12} \mathrm{~s}^{-1}$. A fraction of solid methylamine monolayer of roughly 0.15 diffuses through the water ice surface towards the HOPG substrate. This small amount of methylamine desorbs later with higher binding energies $(5050-8420 \mathrm{~K})$ that exceed that of the crystalline water ice $\left(E_{\mathrm{des}}=4930 \mathrm{~K}\right)$, which is calculated with the same pre-exponential factor $A=10^{12} \mathrm{~s}^{-1}$. The best wetting ability of methylamine compared to $\mathrm{H}_{2} \mathrm{O}$ molecules makes $\mathrm{CH}_{3} \mathrm{NH}_{2} \mathrm{molecules}$ a refractory species for low coverage. Other binding energies of astrophysical relevant molecules are gathered and compared, but we could not link the chemical functional groups (amino, methyl, hydroxyl, and carbonyl) with the binding energy properties. Implications of these high binding energies are discussed.
\end{abstract}

Key words. methods: laboratory: molecular - molecular processes - astrochemistry - techniques: spectroscopic - ISM: molecules dust, extinction

\section{Introduction}

Formamide, $\mathrm{NH}_{2} \mathrm{CHO}$, is a species of great relevance in prebiotic chemistry (Saladino et al. 2012; Barone et al. 2015). This species contains a (quasi) peptide bond $(-\mathrm{NH}-(\mathrm{C}=\mathrm{O}))$ that is very active in the synthesis of nucleic acid bases, carboxylic acids, sugars (Saladino et al. 2012), and amino acids responsible for the formation of proteins. It is also well known to be the precursor species for the formation of purine and pyrimidine bases during the course of chemical evolution leading to the origin of life (Bhushan et al. 2016). Formamide has been observed in the gas phase in several astronomical environments, such as prestellar and protostellar objects (Kahane et al. 2013), massive hot molecular cores (Bisschop et al. 2007), hot corinos (López-Sepulcre et al. 2015), and comets, such as C/20012 F6 (Lemmon), C/2013 R1 (Lovejoy) (Biver et al. 2014), and Hale-Bopp (Bockelée-Morvan et al. 2000).

Formamide has been once tentatively identified in interstellar ices of star-forming regions by ISO-SWS infrared spectra
(Raunier et al. 2004), but it is no longer in the list of confirmed molecules in interstellar ices (Boogert et al. 2015). As for numerous molecules, especially interstellar complex organic molecules, astrochemists would like to put constraint on the formation pathway of formamide. In order to discriminate different scenarios of star formation, solid-state and gas-phase formation routes are usually debated because they imply different physical conditions. For both chemical routes, there are arguments coming from observations and others belonging to the physical or chemical properties of $\mathrm{NH}_{2} \mathrm{CHO}$. On the observational side, López-Sepulcre et al. (2015) have noticed that $\mathrm{NH}_{2} \mathrm{CHO}$ is correlated to isocyanic acid (HNCO) abundances. Furthermore, the first detection of deuterated formamide towards the low protostar IRAS 16293 by ALMA-PILS, which was a D/H ratio of $2 \%$ similar to $\mathrm{HNCO}$ (Coutens et al. 2016), has been found to be in agreement with the hypotheses that these species are chemically related through grain-surface formation. On the other hand, Codella et al. (2017) have explained well the observation of formamide in the brightest shocked region of the 
large-scale molecular outflow L1157-B1 through the gas-phase reactions between $\mathrm{NH}_{2}$ and $\mathrm{H}_{2} \mathrm{CO}$. For prestellar core conditions $(T<10 \mathrm{~K})$, despite the inclusion of this very efficient reaction in their chemical network, Vasyunin et al. (2017) do not really overestimate the abundance of formamide in the prestellar core L1544. In these cold prestellar sources, formamide remains undetected according to Jiménez-Serra et al. (2016). The scenario of the gas-phase formation route of formamide relies on the computational work of Barone et al. (2015) and that of Skouteris et al. (2017), who studied the deuteration aspects and confirmed that the gas-phase route for the formation of formamide in the first cold prestellar phase is in agreement with the observations. The theoretical discussion (Song \& Kästner 2016) about the presence or the absence of the barrier for this key reaction $\left(\mathrm{NH}_{2}+\mathrm{H}_{2} \mathrm{CO} \rightarrow \mathrm{NH}_{2} \mathrm{CHO}+\mathrm{H}\right)$ in the gas phase will end when experimental work is carried on. On the other hand, in the solid state, many experimental reports about the formation of formamide have been published. Energetic electron bombardment of CO- $\mathrm{NH}_{3}$ ice mixtures (Jones et al. 2011), ion irradiation of $\mathrm{H}_{2} \mathrm{O}-\mathrm{HCN}$ ices at $18 \mathrm{~K}$ (Gerakines et al. 2004), and during the warm-up of photolyzed ice mixtures of $\mathrm{H}_{2} \mathrm{O}, \mathrm{CH}_{3} \mathrm{OH}, \mathrm{CO}$, and $\mathrm{NH}_{3}$ (Bernstein et al. 1995), led to the formation of $\mathrm{NH}_{2} \mathrm{CHO}$. Recent laboratory experiments of Fedoseev et al. (2016) have also produced formamide molecules by hydrogenation and UV photolysis of NO in CO-rich interstellar ice analogues. The chemical link in the solid phase of $\mathrm{HNCO}$ and $\mathrm{NH}_{2} \mathrm{CHO}$ has been ruled out by $\mathrm{H}$-bombardment experiments of $\mathrm{HNCO}$ at low surface temperature (Noble et al. 2015), which do not lead to detectable amounts of $\mathrm{NH}_{2} \mathrm{CHO}$ molecules. Our group demonstrates that formamide can be produced with high efficiencies even without the help of external energy (Nguyen et al., in prep.). A last aspect of the solid phase chemical route concerns the binding energy of formamide. Dawley et al. (2014) have investigated thermal desorption of thick mixed $\mathrm{H}_{2} \mathrm{O}-\mathrm{NH}_{2} \mathrm{CHO}$ ices on a silicate $\left(\mathrm{SiO}_{2}\right)$ grain analogue from 70 to $400 \mathrm{~K}$. These authors have observed a delayed desorption peak of the water ice at $160-200 \mathrm{~K}$, resulting from the diffusion of $\mathrm{H}_{2} \mathrm{O}$ molecules during the phase transition of formamide accumulated in the ice, followed by a large desorption profile at higher temperatures (200-380 K), corresponding to the diffusion of molecules through the high surface area of silicate. The desorption activation energy of formamide measured experimentally from $\mathrm{SiO}_{2}$ substrate has been found to be $14.7 \mathrm{kcal} \mathrm{mol}^{-1}$ (or $7397 \mathrm{~K}$ ) with a pre-factor $A=10^{13} \mathrm{~s}^{-1}$. Recently, Wakelam et al. (2017) have estimated the binding energy of formamide on water ice surface to be $(6300 \pm 1890) \mathrm{K}$ using a semi-empirical theoretical approach. The discrepancy can obviously come from the calculation method, but could also find its origin in the amount of $\mathrm{NH}_{2} \mathrm{CHO}$ interacting with the water ice, which is high in the first case (Dawley et al. 2014) and very low in the second case (Wakelam et al. 2017). Experiments performed with thin layers on the surface of the substrate are required for a better comparison. Anyhow, formamide has a very high value of binding energy that is much higher than that of $\mathrm{H}_{2} \mathrm{O}$, which is around $4930 \mathrm{~K}$ for crystalline water ice, estimated from the results of Fraser et al. (2001) using a pre-exponential factor $A=10^{12} \mathrm{~s}^{-1}$. At the current state of the astrochemistry, it is not mandatory to involve the direct formation of formamide on dust grains to explain its observation (or non-observation) in various media, as long as the gas-phase reaction between $\mathrm{NH}_{2}$ and $\mathrm{H}_{2} \mathrm{CO}$ is supposed to be efficient. If the correlation between $\mathrm{HNCO}$ and $\mathrm{NH}_{2} \mathrm{CHO}$ is confirmed at lower spacial scales, it is not due to an obvious link with the solid phase. Finally, even if formamide is easily formed on grains, its return into the gas phase is often more puzzling than other complex organic molecules because of its high binding energy and its very low interaction with water. In summary, the main formation route of $\mathrm{NH}_{2} \mathrm{CHO}$, by gas-phase or surface reactions, has not yet been settled and more observational and experimental work is needed. Another interesting fundamental organic compound in biochemistry studied in this work is the methylamine, $\mathrm{CH}_{3} \mathrm{NH}_{2}$, which is known to be the most abundant aminecontaining molecule after formamide $\left(\mathrm{NH}_{2} \mathrm{CHO}\right)$. Methylamine has been detected in the gas phase through its $202->1_{10} \mathrm{~A}_{\mathrm{a}^{-}}$ state transition in the direction of Sgr B2 and Ori A (Fourikis et al. 1974) towards the giant molecular cloud Sgr B2(N) with a fractional abundance as high as $3 \times 10^{-7}$ relative to molecular hydrogen (Nummelin et al. 2000). It has also been detected in the coma of comet 67P/Churyumov-Gerasimenko (Altwegg et al. 2016) by the Rosetta space mission. In the gas phase, the formation of the methylamine molecules is completely dependent on radicals $\mathrm{CH}_{3}^{\bullet}$ and $\mathrm{NH}_{2}^{\bullet}$ produced by UV photons (Garrod et al. 2008). In the solid phase, the hydrogenation experiments of HCN molecules by $\mathrm{H}$ atoms at low surface temperature (Theule et al. 2011) have shown the formation of the fully saturated species $\mathrm{CH}_{3} \mathrm{NH}_{2}$ with methanimine as an intermediate. The desorption of these molecules occurred between 140 and $150 \mathrm{~K}$, at slightly lower temperatures than the desorption of the amorphous water ice in their experimental conditions. Recent thermal desorption experiments of Souda (2016) have shown that methylaminewater interaction is influenced by the porosity of the ASW ice. An efficient incorporation of $\mathrm{CH}_{3} \mathrm{NH}_{2}$ molecules in the porous water ice film, deposited on Nickel $\mathrm{Ni}(111)$ substrate at $20 \mathrm{~K}$ has been observed, with a narrow desorption peak at $160 \mathrm{~K}$, during water ice crystallization. In contrast, no diffusion of $\mathrm{CH}_{3} \mathrm{NH}_{2}$ molecules in the film interior of the non-porous water ice, deposited at surface temperature $120 \mathrm{~K}$, has been observed in its TPD spectra, even by hydrogen bonding formation with $\mathrm{H}_{2} \mathrm{O}$ molecules. Despite this advanced work, no experimental values for the desorption energies of methylamine have been provided on water ice. However, a desorption energy value (6584 K) of $\mathrm{CH}_{3} \mathrm{NH}_{2}$ is given in http: //kida.obs.u-bordeaux $1 . \mathrm{fr} /$ species/154/CH3NH2.html from a previous estimation of the OSU gas-grain code of Eric Herbst's group. Within molecular clouds, the desorption of molecules from icy mantles back into the gas-phase occurs either by thermal, or non-thermal processes. Non-thermal desorption of molecules may result from the exothermic reactions occurring on the grain surface (Duley \& Williams 1993; Vasyunin \& Herbst 2013; Dulieu et al. 2013; Minissale et al. 2016) and the impact of cosmic rays or ultraviolet photons (Leger et al. 1985; Hartquist \& Williams 1990). Thermal desorption process occurs during the collapse of the dense clouds and the birth of protostars (Garrod et al. 2007). The gravitational energy is converted into radiation, provoking the warm-up of the grain and the desorption of molecules from the icy mantle to the gas environment. In laboratory, temperatureprogrammed desorption (TPD) is the most effective method for the measurement of ice sublimations over a significantly shorter timescale and for the determination of the energy required for desorption.

In this work, we investigate thermal desorption experiments of formamide $\left(\mathrm{NH}_{2} \mathrm{CHO}\right)$ and methylamine $\left(\mathrm{CH}_{3} \mathrm{NH}_{2}\right)$ adsorbate in the sub-monolayer and monolayer regimes on two surfaces. These surfaces are that of the highly orientated pyrolytic graphite (HOPG) as a laboratory model for carbonaceous grains and the surface of the $\mathrm{H}_{2} \mathrm{O}$ non-porous amorphous solid water (np-ASW) ice, covering the HOPG substrate and acting as an extremely relevant astrophysical surface analogue. The aim of 
this work is to understand the interaction of these two amino molecules with the water ice and to study the effect of the graphitic substrate on the desorption processes. For this purpose, we determine the desorption energy distributions of formamide and methylamine on both surfaces, using TPD measurements and Polanyi-Wigner equation. We compare these distributions to the binding energy of pure water ice. This paper is organized as follows: Sect. 2 explains the experimental methods, Sect. 3 presents the experimental results and the TPD measurements of formamide $\left(\mathrm{NH}_{2} \mathrm{CHO}\right)$ and methylamine $\left(\mathrm{CH}_{3} \mathrm{NH}_{2}\right)$ on graphite (HOPG) and on np-ASW ice surfaces, Sect. 4 describes the model developed to measure the desorption energy distributions of formamide and methylamine molecules from graphite and water ice surfaces, Sect. 5 presents the discussion of the results, and finally Sect. 6 summarizes the main conclusions of this work.

\section{Experimental methods}

The experiments were performed using the FORMOLISM (FORmation of MOLecules in the InterStellar Medium) apparatus. The set-up is dedicated to study the interaction of atoms and molecules on surfaces of astrophysical interest. The experimental set-up is briefly described here and more details are given in earlier papers (Amiaud et al. 2007; Chaabouni et al. 2012). The apparatus is composed of an ultra-high vacuum (UHV) stainless steel chamber with a base pressure $10^{-10}$ mbar. The sample holder is located in the centre of the main chamber. It is thermally connected to a cold finger of a closed-cycle He cryostat. The temperature of the sample is measured in the range 40 $350 \mathrm{~K}$ by a calibrated platinum $(\mathrm{Pt})$ diode clamped to the sample holder, which is made of $1 \mathrm{~cm}$ diameter copper block, covered with a highly orientated pyrolytic graphite (HOPG, ZYA-grade) slab.

In our laboratory experiments, the viscous, liquid formamide is introduced in a pyrex flask, which is placed in a ceramic bath containing a silicone oil acting as a regulator for the temperature. Because of the low source vapour pressure of formamide in the beam line at room temperature, the liquid is warmed up to $50{ }^{\circ} \mathrm{C}$ using a heating plate with a motor speed of 280 revolutions per minute. Methylamine compound is also used under its aqueous solution with a weight percent in water of $40 \mathrm{wt} \%$, meaning that there is $40 \mathrm{~g}$ of $\mathrm{NH}_{2} \mathrm{CH}_{3}$ solute for every $100 \mathrm{~g}$ of water solvent. Methylamine is more volatile than formamide and its source pressure at the inlet of the beam line is set to $1.00 \mathrm{mbar}$ at room temperature. At these experimental conditions, formamide and methylamine beams were aimed at the surface of the HOPG substrate, held at $40 \mathrm{~K}$, for several deposition times, using a triply differentially pumped beam line, orientated $60^{\circ}$ with respect to the surface of the sample holder.

The UHV chamber is also equipped with a movable quadrupole mass spectrometer (Hiden Analytical QMS) operating in the range 1-100 amu (atomic mass unit) with a Channeltron detector. The QMS is orientated face-on to the beam line to characterize the gas composition of formamide and methylamine beams. It is placed $5 \mathrm{~mm}$ in front of the surface of the sample holder to apply the TPD technique using a custom LabView software that maintains a linear heating rate of $0.2 \mathrm{~K} \mathrm{~s}^{-1}$. During the warm-up phase of the sample, from 40 to $240 \mathrm{~K}$, the species desorbing from the surface into the gas phase are ionized, or fragmented into cracking patterns, by electron impact in the ion source of the QMS. The TPD curves shown in next sections exhibit the most intensive signals monitoring with the
QMS of the intact parent molecules $\mathrm{NH}_{2} \mathrm{CHO}(\mathrm{m} / z=45 \mathrm{amu})$, $\mathrm{NH}_{2} \mathrm{CH}_{3}(m / z=31 \mathrm{amu})$, and $\mathrm{H}_{2} \mathrm{O}(\mathrm{m} / z=18 \mathrm{amu})$, which are only converted into positive ions by electron impact ionization. The QMS is also moved to the upper position to prepare the films of the non-porous amorphous solid water (np-ASW) ice on the graphite surface, using a micro-channel array doser $(1 \mathrm{~cm}$ in diameter), located $2 \mathrm{~cm}$ in front of the surface in the UHV chamber. The np-ASW ice film of $10 \mathrm{ML}$ thickness is grown on top of the graphite (HOPG) surface, maintained at the temperature of $110 \mathrm{~K}$, by spraying water vapour under a constant deposition pressure in the vacuum chamber of $2 \times 10^{-9}$ mbar. Water vapour is obtained from deionized liquid $\mathrm{H}_{2} \mathrm{O}$, purified by several pumping cycles under cryogenic vacuum conditions (Noble et al. 2012). After deposition, the temperature of the surface is kept constant at $110 \mathrm{~K}$ for $30 \mathrm{~min}$, until the background pressure in the vacuum chamber is stabilized at $10^{-10} \mathrm{mbar}$. Then the sample was cooled to the base temperature $40 \mathrm{~K}$ prior to formamide or methylamine deposition. During the cooling of the water ice from 110 to $40 \mathrm{~K}$, the structure and the morphology of the water ice is not changed. Water ice deposited at $110 \mathrm{~K}$ remains in the same compact (non-porous) amorphous state at $40 \mathrm{~K}$.

Since our desorption experiments are performed in the submonolayer and monolayer regimes, the dimensionless surface coverage $\left(\theta=N / N_{\text {mono }} \leq 1\right)$ is defined as the number density of molecules exposed on the surface $(N)$ by the maximum surface number density of molecules $N_{\text {mono }}$ prior to multi-layer desorption (Noble et al. 2012). At surface coverage saturation $(\theta=1)$, the first monolayer of molecules covering the surface is defined as the maximum number density of molecules that populate $10^{15}$ adsorption site per $\mathrm{cm}^{2}$ on a flat surface, such as graphite. This definition of one monolayer unit $\left(1 \mathrm{ML}=10^{15}\right.$ molecules $\left.\mathrm{cm}^{-2}\right)$ is kept over this study; this includes amorphous surfaces, such as non-porous ASW ice, where the saturation of the first layer of molecules can thus be observed at a value, which differs from the exact value of the defined $1 \mathrm{ML}$. In our experiments, the first monolayer of solid formamide covering the surface of graphite at $40 \mathrm{~K}$ was reached after $90 \mathrm{~min}$ of exposure time, and that of solid methylamine after beam deposition during $10 \mathrm{~min}$. The fluxes of formamide and methylamine molecules coming from the gas phase and hitting the surface of the sample holder are defined as the ratio of the amount of molecules in the designed $1 \mathrm{ML}$ divided by the exposure time required for surface saturation. These fluxes derived from TPD data and the method described in Noble et al. (2012) are estimated to be $2.6 \times 10^{10}$ molecules $\mathrm{cm}^{-2} \mathrm{~s}^{-1}$ for $\mathrm{NH}_{2} \mathrm{CHO}$ beam and $1.6 \times 10^{12}$ molecules $\mathrm{cm}^{-2} \mathrm{~s}^{-1}$ for $\mathrm{CH}_{3} \mathrm{NH}_{2}$ beam.

\section{Experimental results}

\subsection{Formamide}

\subsubsection{Formamide on graphite surface}

Figure 1 shows the desorption curves of formamide $\left(\mathrm{NH}_{2} \mathrm{COH}\right)$ given by the QMS signals of $m / z=45$, for several exposure doses $(0.15,0.30,0.61$, and $1.00 \mathrm{ML})$ on the graphite HOPG surface. The fifth TPD spectrum corresponds to the multi-layer regime of formamide given by the higher exposure dose of 1.66 ML. All the TPD spectra exhibit desorption peaks between 160 and $200 \mathrm{~K}$. Although the integrated area under the TPD curves increases with the exposure dose of formamide from 0.15 to $1.66 \mathrm{ML}$, the desorption peak remains at the same temperature of $176 \mathrm{~K}$, mainly for surface coverage higher than 0.30 ML. For the lowest dose of $0.15 \mathrm{ML}$, the TPD peak is shifted to a slightly 


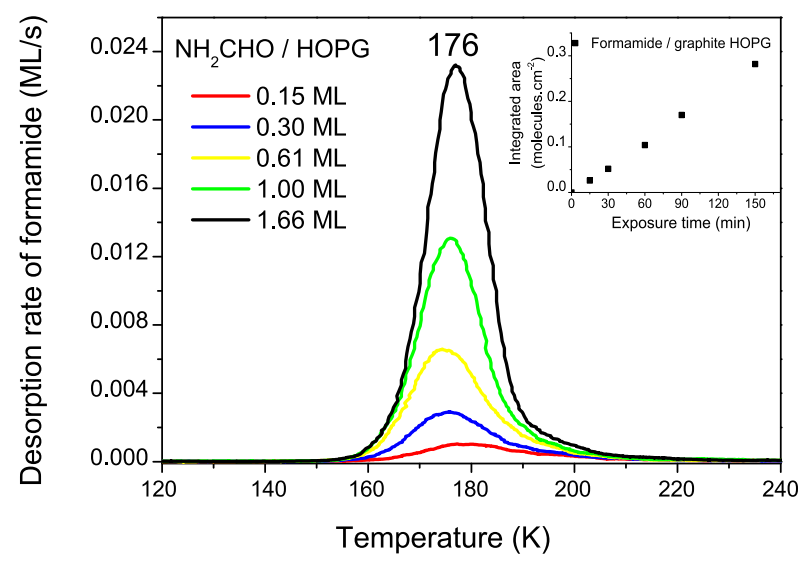

Fig. 1. Desorption rates of formamide $\left(\mathrm{NH}_{2} \mathrm{CHO} ; m / z=45\right)$, expressed $\left(\mathrm{ML} \mathrm{s}^{-1}\right)$ as a function of the temperature of the surface for several exposure doses $(0.15,0.30,0.61,1.00$, and $1.66 \mathrm{ML})$ of solid formamide on the cold HOPG surface at $40 \mathrm{~K}$. The linear heating rate of the samples is $0.2 \mathrm{~K} \mathrm{~s}^{-1}$. The linear dependence of the integrated area under the TPD curves as a function of the exposure time is shown in the inset.

higher temperature compared to the higher doses. The inset in Fig. 1 shows the linear evolution of the integrated areas under the TPD curves (for surface dose up to $1 \mathrm{ML}$ and above) as a function of the exposure times.

\subsubsection{Formamide on $n p-A S W$ ice}

Figure 2 shows the desorption curve of solid $\mathrm{NH}_{2} \mathrm{CHO}(\mathrm{m} / z=$ 45 ) on np-ASW ice, peaking at $176 \mathrm{~K}$. For comparison, the desorption curve of the non-porous ASW ice film, given by the signal $(m / z=18)$ at $150 \mathrm{~K}$, is also shown. Formamide is clearly desorbing from the surface at a higher temperature than the water ice. The TPD curve of formamide from the water ice surface is similar to that obtained previously from the graphite HOPG surface for the same exposure dose of $1 \mathrm{ML}$. This means that the desorption of formamide molecules into the gas phase is not affected by the water ice substrate. The calculations of the integrated areas below the TPD curves show that more than 0.95 ML of solid formamide is likely to diffuse from the surface of the water ice towards the graphite HOPG substrate. This diffusion probably occurs during the warm-up phase of the sample and the reorganization of the water ice. Since our TPD experiments last few minutes, the diffusion timescale of the molecules from the surface of the water ice to the graphitic substrate is expected to be about few seconds. Because formamide desorbs after water, its binding energy from the HOPG surface is expected to be higher than that of $\mathrm{H}_{2} \mathrm{O}$ molecules.

\subsection{Methylamine}

Similarly to formamide, the adsorption-desorption experiments of methylamine $\mathrm{CH}_{3} \mathrm{NH}_{2}$ molecules were investigated both on graphite (HOPG) and on np-ASW ice surfaces.

\subsubsection{Methylamine on graphite surface}

Figure 3 shows the desorption curves of methylamine $(\mathrm{m} / \mathrm{z}=31)$ for several exposure doses (ML) on graphite surface held at $40 \mathrm{~K}$. For very small doses $(0.18,0.26 \mathrm{ML})$, molecules occupy the most energetically favourable adsorption sites and are tightly bound to the surface of the HOPG, desorbing late from the surface, at temperatures up to $160 \mathrm{~K}$. This small TPD peak is assigned to the

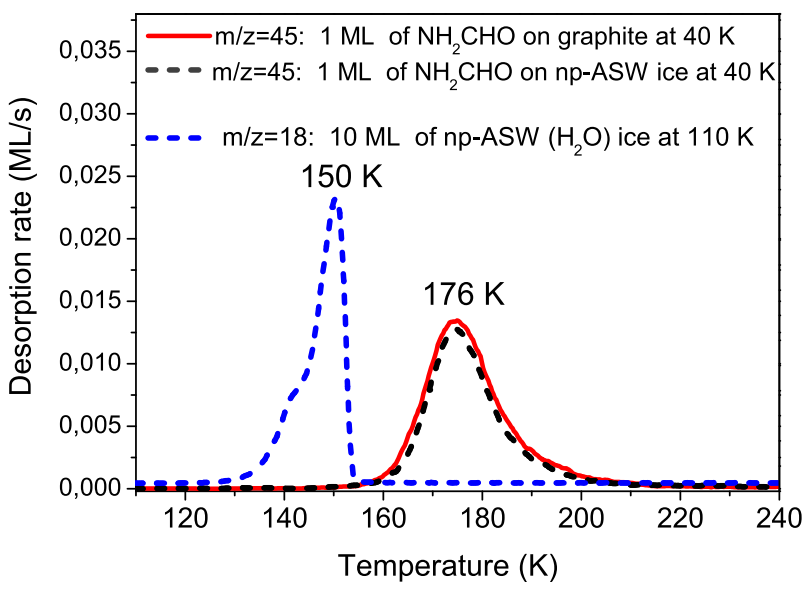

Fig. 2. TPD curves of formamide $\left(\mathrm{NH}_{2} \mathrm{CHO}\right)$ giving the desorption rates $\left(\mathrm{ML} \mathrm{s}^{-1}\right)$ of the mass $(\mathrm{m} / z=45)$ as a function of the temperature of the surface $(\mathrm{K})$. The red line indicates the TPD signal of $\mathrm{NH}_{2} \mathrm{CHO}$ deposited on graphite (HOPG) surface at $40 \mathrm{~K}$; the black dashed line shows the TPD signal of $\mathrm{NH}_{2} \mathrm{CHO}$ deposited on the np-ASW ice surface at $40 \mathrm{~K}$; and the blue dashed line indicates the TPD signal of $\mathrm{H}_{2} \mathrm{O}(m / z=18)$ for $10 \mathrm{ML}$ thickness of the np-ASW ice film prepared at $110 \mathrm{~K}$ on the HOPG surface and cooled down to $40 \mathrm{~K}$ (scaled by $0.0007)$.

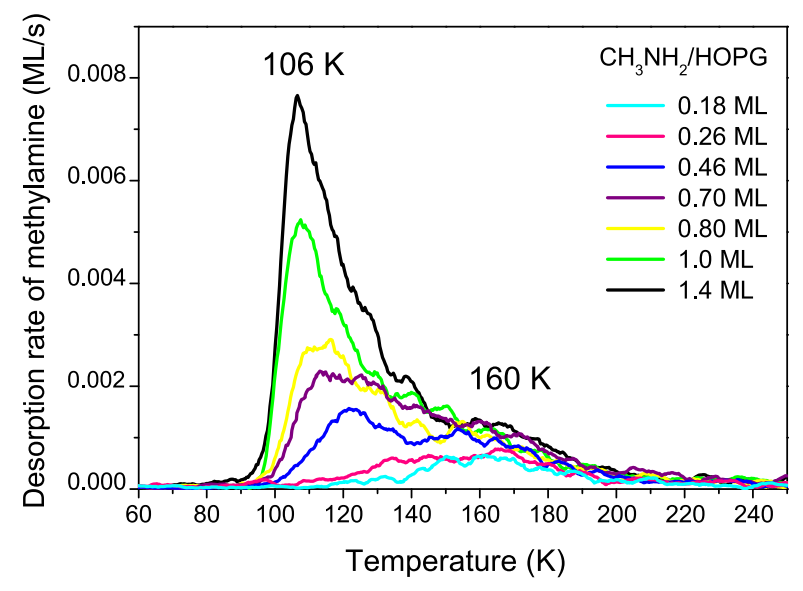

Fig. 3. Desorption rates, expressed $\left(\mathrm{ML} \mathrm{s}^{-1}\right)$, of methylamine $\left(\mathrm{CH}_{3} \mathrm{NH}_{2}\right)$ as a function of the temperature of the surface $(\mathrm{K})$ for several exposure doses of solid methylamine $(0.18,0.26,0.46,0.70,0.80,1.0$, and $1.40 \mathrm{ML}$ ) on the cold HOPG surface at $40 \mathrm{~K}$. The linear heating rate of the samples is $0.2 \mathrm{~K} \mathrm{~s}^{-1}$.

strong interaction of the $\mathrm{NH}_{2} \mathrm{CH}_{3}$ molecules with the graphitic surface in the sub-monolayer regime. As the surface coverage increases, molecules are forced to populate progressively less tightly bound sites of the graphitic HOPG surface, provoking earlier desorption at about $113 \mathrm{~K}$. The area of the second desorption peak of $\mathrm{CH}_{3} \mathrm{NH}_{2}$ at $113 \mathrm{~K}$ increases with the increase of the exposure doses in the sub-monolayer regime, and its maximum shifts towards a lower temperature $(106 \mathrm{~K})$ once the surface coverage is saturated and the first monolayer is formed. The strong desorption peak at $106 \mathrm{~K}$ for $1.40 \mathrm{ML}$ corresponds to the onset of the multi-layer desorption of solid methylamine, where $\mathrm{CH}_{3} \mathrm{NH}_{2}$ is bound to $\mathrm{CH}_{3} \mathrm{NH}_{2}$ ice by hydrogen bonds.

\subsubsection{Methylamine on $\mathrm{np}-\mathrm{ASW}$ ice}

Figure 4 shows the TPD curves of solid methylamine $(\mathrm{m} / \mathrm{z}=31)$ from the np-ASW ice surface for two small doses $(0.30$ and 
$0.35 \mathrm{ML}$ ) deposited on the surface during 5 and $6 \mathrm{~min}$, respectively (thick red and magenta lines). These curves are compared to the TPD curve of solid methylamine on the graphite (HOPG) surface for a $1 \mathrm{ML}$ exposure dose (thin red line) and to the $\mathrm{H}_{2} \mathrm{O}$ TPD curve $(m / z=18)$ of pure np-ASW ice, with $10 \mathrm{ML}$ thickness, grown on the HOPG surface at $110 \mathrm{~K}$ (blue dashed line). As shown in Fig. 4, the large TPD peak of solid $\mathrm{CH}_{3} \mathrm{NH}_{2}$ (1 ML) from the HOPG surface shows a multi-layer desorption peak at lower surface temperatures centred at $106 \mathrm{~K}$, a shoulder at about $140-150 \mathrm{~K}$ resulting from the mixture of the methylamine with the water coming from the aqueous phase, and a long desorption tail at higher temperatures, up to $220 \mathrm{~K}$. When $\mathrm{CH}_{3} \mathrm{NH}_{2}$ is deposited on top of the np-ASW ice film of 10 ML thickness, prepared at $110 \mathrm{~K}$ and cooled down to $40 \mathrm{~K}$, the maximum of the desorption peak of methylamine is shifted to the higher temperature, $137 \mathrm{~K}$, and a large desorption peak with a maximum centred at $160 \mathrm{~K}$ appears as a tail at higher surface temperatures up to $220 \mathrm{~K}$. This desorption behaviour of methylamine on the np-ASW ice is observed for two close exposure doses of 0.30 and $0.35 \mathrm{ML}$. The desorption peaks at $137 \mathrm{~K}$, which occur before the desorption of pure water ice at $150 \mathrm{~K}$, and even the crystallization phase of $\mathrm{H}_{2} \mathrm{O}$ at about $145 \mathrm{~K}$, correspond to $\mathrm{CH}_{3} \mathrm{NH}_{2}$ molecules desorbing from the surface of the water ice. Our experimental results show that, when increasing slightly the exposure dose of methylamine on the np-ASW ice surface from 0.30 to $0.35 \mathrm{ML}$, the fraction of $\mathrm{CH}_{3} \mathrm{NH}_{2}$ ice desorbing from the water ice surface at $137 \mathrm{~K}$ increases from 0.16 to $0.21 \mathrm{ML}$, while those desorbing directly from the HOPG surface at $T \geq 160 \mathrm{~K}$ decreases slightly from 0.16 to $0.14 \mathrm{ML}$, respectively. This means that by increasing the amount of methylamine on top of the water ice surface, $\mathrm{CH}_{3} \mathrm{NH}_{2}$ molecules bind further with the water ice by hydrogen bonds and desorb between 120 and $140 \mathrm{~K}$, rather than diffuse through the water ice surface and desorb later from the HOPG substrate at $160-220 \mathrm{~K}$. The fraction of the refractory $\mathrm{CH}_{3} \mathrm{NH}_{2}$ molecules desorbing from the HOPG substrate after water ice sublimation is about $0.15 \mathrm{ML}$.

Our results are partially in agreement with those of Souda (2016), who observed a broad TPD curve of methylamine from the np-ASW ice of $\mathrm{D}_{2} \mathrm{O}(8 \mathrm{ML})$, deposited at $120 \mathrm{~K}$ on the nickel $\mathrm{Ni}(111)$ substrate. This latter comprises two desorption peaks: one peak at $120 \mathrm{~K}$ corresponding to multilayer desorption of methylamine and another at about $150 \mathrm{~K}$ corresponding to methylamine mixed with water coming from the aqueous solution. In addition, the TPD spectrum of Souda (2016) shows no desorption peak of methylamine at surface temperature $160 \mathrm{~K}$ and above, suggesting that, in contrast to our case, no strong interaction between methylamine and the underlying $\mathrm{Ni}(111)$ substrate takes place in their experiments. If our experiments performed on the np-ASW ice of $10 \mathrm{ML}$ thickness allowed the incorporation of methylamine from the water ice surface towards the graphite substrate, one can conclude that the diffusion of methylamine molecules through the non-porous water ice surface depends on the substrate below the water ice (HOPG, Ni). The nickel Ni(111) surface is expected to have fewer energetic binding sites than HOPG surface. However, if differences of substrates are seen for methylamine, one could say that similar differences are expected for formamide. The role of the substrate is discussed later.

\section{Analysis}

A simple mathematic model has been developed to fit the TPD curves of formamide and methylamine in the sub-monolayer and monolayer regimes. At any surface coverage, thermal desorption

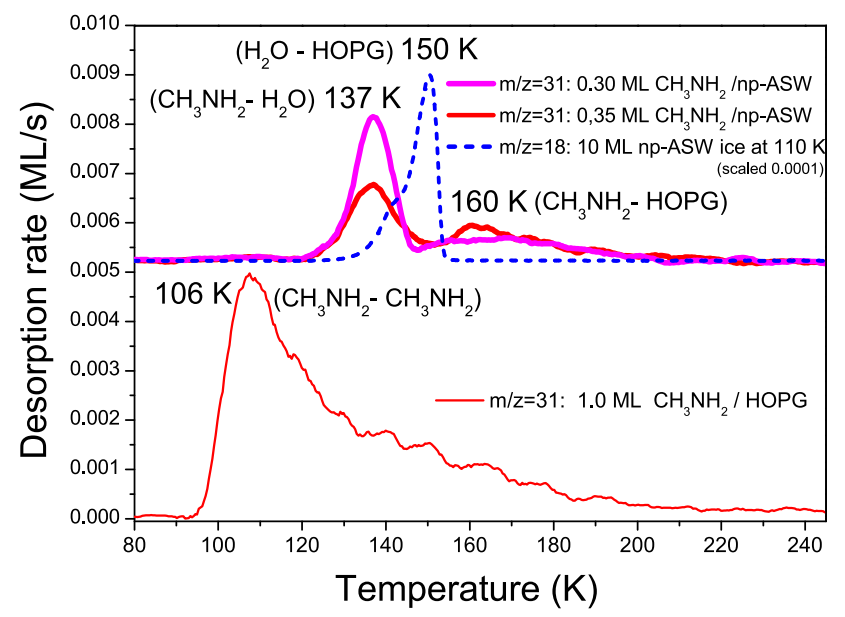

Fig. 4. TPD curves of methylamine giving the desorption rates $\left(\mathrm{ML} \mathrm{s}^{-1}\right)$ of the mass $(m / z=31)$ as a function of the temperature of the surface $(\mathrm{K})$. The thin red line indicates $1 \mathrm{ML}$ of $\mathrm{CH}_{3} \mathrm{NH}_{2}$ deposited on graphite HOPG substrate at $40 \mathrm{~K}$; the thick red line represents $0.30 \mathrm{ML}$ of $\mathrm{CH}_{3} \mathrm{NH}_{2}$ deposited on the np-ASW ice surface held at $40 \mathrm{~K}$; the thick magenta line indicates $0.35 \mathrm{ML}$ of $\mathrm{CH}_{3} \mathrm{NH}_{2}$ deposited on the np-ASW ice surface at $40 \mathrm{~K}$; and the blue dashed line represents TPD curve of $\mathrm{H}_{2} \mathrm{O}(\mathrm{m} / \mathrm{z}=18)$ for $10 \mathrm{ML}$ of the np-ASW ice film prepared at $110 \mathrm{~K}$ on the HOPG surface and cooled down to $40 \mathrm{~K}$ (scaled by 0.001 ).

of molecules from the surface into the gas phase can be described in terms of an Arrhenius law, given by the Polanyi-Wigner Eq. (1) (Noble et al. 2012; Dohnálek et al. 2001)

$r(T)=-\frac{\mathrm{d} N}{\mathrm{~d} t}=A N^{a} \mathrm{e}^{-E_{\mathrm{des}} / k_{\mathrm{B}} T}$,

where $r(T)$ is the desorption rate (molecule $\mathrm{cm}^{-2} \mathrm{~s}^{-1}$ ), $N$ is the number density of molecules adsorbed on the surface, expressed (molecules $\mathrm{cm}^{-2}$ ), $a$ is the order of the desorption process, $A$ is the pre-exponential factor expressed (molecule ${ }^{-a+1} \mathrm{~cm}^{2 a-2} \mathrm{~s}^{-1}$ ), which can be considered to be the attempt frequency of molecules at overcoming the barrier to desorption, $k_{\mathrm{B}}$ is the Boltzmann constant $\left(k_{\mathrm{B}}=1.38 \times 10^{-23} \mathrm{~J} \mathrm{~K}^{-1}\right), t$ is the time (s), $T$ is the absolute temperature of the surface $(\mathrm{K})$, and $E_{\mathrm{des}}$ is the activation energy for desorption $\left(\mathrm{kJ} \mathrm{mol}^{-1}\right)$ or $(\mathrm{K})$, where $1 \mathrm{~kJ} \mathrm{~mol}^{-1}=120 \mathrm{~K}$.

In the particular case of simple molecular adsorption, the pre-exponential factor $A$ may also be equated with the frequency of vibration of the bond between the molecule and substrate; this is because every time this bond is stretched during the course of a vibrational cycle can be considered an attempt to break the bond and hence an attempt at desorption. However, we point out that this is a simplistic view of a complex problem. The physical observable parameter is the desorption flux; the pre-exponential factor and the binding energy are actually two degenerated parameters linked in the Polanyi-Wigner equation. Therefore, at anytime, a couple of solutions $\left(A, E_{\mathrm{des}}\right)$ should be considered.

Because the peaks of the TPD curves of formamide appear at a single temperature value for all the exposure doses up to 1.61 ML, the desorption of formamide is considered to be of first order, and the desorption energy is expected to be dependent on the coverage (Fraser et al. 2001).

For TPD of first order, $a=1$, the desorption rate $r(T)$ become

$r(T)=-\frac{\mathrm{d} N}{\mathrm{~d} t}=A N \mathrm{e}^{-E_{\mathrm{des}} / k_{\mathrm{B}} T}$, 
where the pre-exponential factor $A$ for desorption $\left(\mathrm{s}^{-1}\right)$.

The desorption rate $r(T)\left(\mathrm{ML} \mathrm{s}^{-1}\right)$ can be expressed using Eq. (3)

$r(T)_{\mathrm{ML} \mathrm{s}^{-1}}=\frac{r(T)}{\beta^{-1}\left(\int_{T_{\min }}^{T_{\max }} \frac{\mathrm{d} N}{\mathrm{~d} t} \cdot \mathrm{d} T\right)}$,

where $\left(\int_{T_{\min }}^{T_{\max }} \frac{\mathrm{d} N}{\mathrm{~d} t} \cdot \mathrm{d} T\right)$ is the integrated area below the TPD curve of the designed $1 \mathrm{ML}$ exposure dose between $T_{\min }$ and $T_{\max }$.

In this model, we consider that each exposure dose $N$ (ML) of molecules on the surface is the sum of the different fraction exposure doses $N_{i}(\mathrm{ML})$,

$N=\sum_{i=1}^{n} N_{i}=N_{1}+N_{2}+\cdots$,

where $N_{i}$ is the population of molecules desorbing from the surface with a desorption energy $E_{i}$ at a surface temperature $T$.

We also assume that the desorption rate $r(T)$ is the sum of the desorption rates $r_{i}(T)$, i.e.

$r(T)=\sum_{i=1}^{n} r_{i}(T)=A N_{1} \mathrm{e}^{-E_{1} / k_{\mathrm{B}} T}+A N_{i} \mathrm{e}^{-E_{i} / k_{\mathrm{B}} T}+\cdots$,

where

$r_{i}(T)=A N_{i} \mathrm{e}^{-E_{i} / k_{\mathrm{B}} T}$

is the desorption rate of the molecular population, $N_{i}$, desorbing from the surface at a temperature $T$, with a pre-exponential factor $A$, and a desorption energy $E_{i}$.

To fit the TPD data for an exposure dose $N$ of molecules on the surface, we use the desorption rate $r(T)$, given by Eq. (5), then we set two values $E_{\min }$ and $E_{\max }$ for the desorption energy of the molecules from the surface, and we choose a value for the pre-exponential factor $A$. When we run the program, we obtain the different populations $N_{i}$ of molecules desorbing from the surface with the desorption energy $E_{i}$, at a surface temperature $T$, varying from $T_{\min }$ to $T_{\max }$. The best fit of the TPD data is obtained when the calculated curve matches well the experimental results, and the three computational parameters $\left(A, E_{i}, N_{i}\right)$ are well constrained, where the pre-exponential factor $A$ is between $10^{12}$ and $10^{18} \mathrm{~s}^{-1}$, the desorption energy barrier $E_{i}$ is between $E_{\min }$ and $E_{\max }$, and all the surface populations $N_{i}$ satisfy the relation (4).

\subsection{Desorption energies of formamide}

The top panel of Fig. 5 shows the best fits of the TPD curves of formamide for various surface doses $(0.14,0.30,0.61$ and 1.0 ML) on the graphite (HOPG) surface. These best fits are derived from Eq. (5) with a pre-exponential factor $A=10^{18} \mathrm{~s}^{-1}$. The use of a low pre-exponential factor $\left(A=10^{12} \mathrm{~s}^{-1}\right)$ in our modelling simulations does not reproduce the TPD curves on the graphite surface perfectly. The bottom panel of Fig. 5 shows the surface population $N_{i}$ of formamide molecules (ML) as a function of the desorption energy $E_{i}(\mathrm{~K})$ on the graphite (HOPG) surface for the first monolayer exposure coverage $(N=1 \mathrm{ML})$. As shown in Fig. 5, bottom panel, most of the surface population ( $\sum_{i=1}^{n} N_{i}=\sim 0.97 \mathrm{ML}$ ) of formamide on HOPG surface releases into the gas phase with a desorption energy distribution, ranging from 7460 to $9380 \mathrm{~K}$.
The same desorption energy distribution (7460-9380 K) is obtained by fitting the TPD data of formamide deposited on top of the np-ASW ice film of $10 \mathrm{ML}$ thickness, covering the graphitic HOPG substrate. This main result is explained by the fast and efficient (>95\%) diffusion of $\mathrm{NH}_{2} \mathrm{CHO}$ molecules from the water ice surface towards the HOPG substrate, at surface temperature, $40 \mathrm{~K}$, or more probably during the warming-up phase of the ices. The bottom panel of Fig. 5 also shows that for a pre-exponential factor $A=10^{18} \mathrm{~s}^{-1}$, the maximum of the desorption energy distribution of formamide $(7700 \mathrm{~K})$ is higher than that of pure amorphous water ice $\left(E_{\mathrm{des}}=6490 \mathrm{~K}\right)$, calculated with the same pre-exponential value $A=10^{18} \mathrm{~s}^{-1}$ from the parameters $\left(E_{\mathrm{des}}, A\right)$ of the amorphous water ice (Fraser et al. 2001). This means that $\mathrm{NH}_{2} \mathrm{CHO}$ molecules are more tightly physisorbed to the surface of the HOPG substrate than $\mathrm{H}_{2} \mathrm{O}$ molecules.

\subsection{Desorption energies of methylamine}

Similar calculations of the desorption energy distribution of methylamine have been carried out both on graphite HOPG and np-ASW ice surfaces. Assuming a first order desorption process of methylamine on graphite surface, the best fits of the TPD curves for various values of the surface exposure coverage, $N$ $(0.25,0.46,0.71$, and 1.0 ML) of methylamine, obtained from the model with the pre-exponential factor $A=10^{12} \mathrm{~s}^{-1}$, are shown in Fig. 6.

The top panel of Fig. 7 shows the surface population $N_{i}$ (ML) of solid methylamine on graphite (HOPG) surface as a function of the desorption energy $E_{i}$ of methylamine $(\mathrm{K})$, for the first monolayer exposure coverage $(N=1 \mathrm{ML})$. The desorption energy distribution of methylamine from graphite is found to range between 3010 and $8420 \mathrm{~K}$, where a large percentage ( $\sim 0.80 \mathrm{ML})$ of molecules desorbing with low binding energies (3010-4454 K) correspond to the multi-layer and monolayer desorptions of $\mathrm{CH}_{3} \mathrm{NH}_{2}$ species from the graphite surface. The range of the desorption energy $(5050-8420 \mathrm{~K})$ is assigned to the surface population $(\sim 0.15 \mathrm{ML})$ of methylamine that desorbs from the very energetic adsorption sites of the graphite (HOPG) surface.

In the case of Fig. 7, bottom panel, where an exposure dose $N=0.30 \mathrm{ML}$ of solid methylamine is deposited on top of the np-ASW ice film, the desorption energy distribution of these molecules is reduced to the range (3900-8420 K), with traces of small energies (2770-3610 K) corresponding to methylamine multi-layer desorption. The bottom panel of Fig. 7 also shows that a surface population of about $0.15 \mathrm{ML}$ of $\mathrm{CH}_{3} \mathrm{NH}_{2}$ leaves the water ice surface with desorption energies (3900$4500 \mathrm{~K})$, which is lower than the binding energy value $(4930 \mathrm{~K})$ of crystalline water ice, calculated with the same pre-exponential factor $A=10^{12} \mathrm{~s}^{-1}$ from the desorption parameters $\left(E_{\mathrm{des}}, A\right)$ of Fraser et al. (2001). Furthermore, the desorption energies $(5050-8420 \mathrm{~K})$, which are higher than those of the amorphous water ice, are attributed to the fraction $\left(\sum_{i=1}^{n} N_{i}=\sim 0.15 \mathrm{ML}\right)$ of methylamine population that diffuses through the water ice surface towards the highest binding sites of the HOPG substrate, and then desorbs into the gas phase after water ice sublimation.

\section{Discussion}

We developed a model using the Polanyi-Wigner equation to reproduce the TPD profiles and determine the desorption energy distributions of $\mathrm{NH}_{2} \mathrm{CHO}$ and $\mathrm{CH}_{3} \mathrm{NH}_{2}$ molecules on graphite 
H. Chaabouni et al.: Thermal desorption of formamide and methylamine
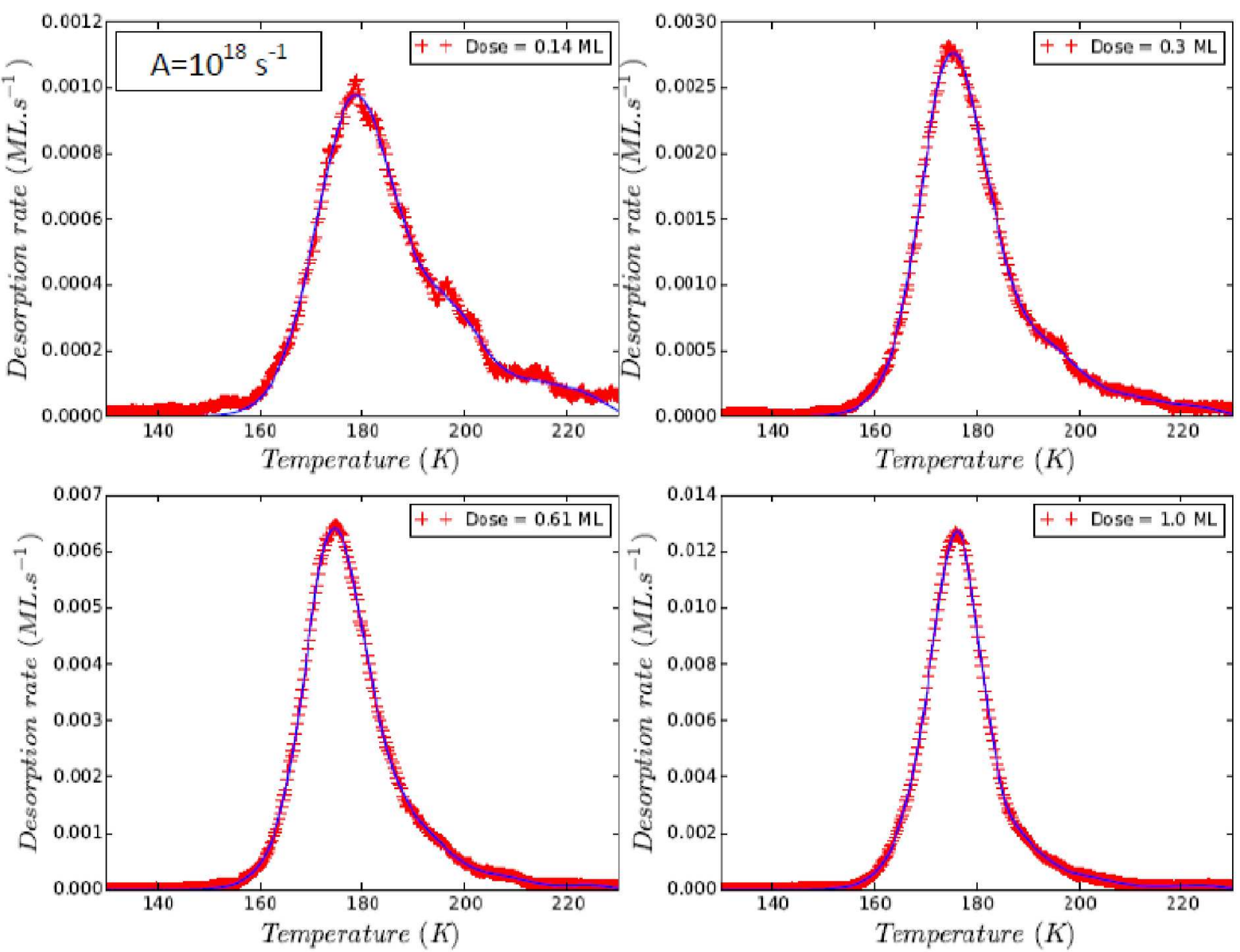

Formamide (N=1 ML) on graphite

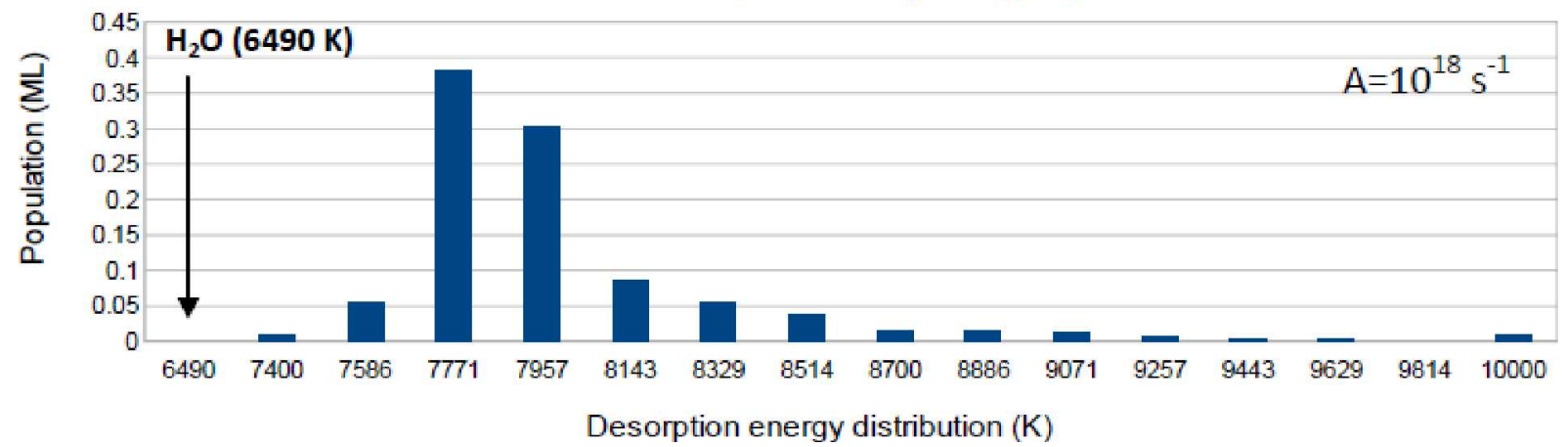

Fig. 5. Modelling results of the desorption rates $\left(\mathrm{ML} \mathrm{s}^{-1}\right)$ and the desorption energy distribution (K) of formamide on graphite (HOPG) surface. Top panel: red crosses indicate TPD data of $\mathrm{NH}_{2} \mathrm{CHO}(\mathrm{m} / \mathrm{z}=45)$ on HOPG surface for different exposure doses of $0.14,0.30,0.61$, and 1.0 ML; blue lines: the best fits of the TPD curves of $\mathrm{NH}_{2} \mathrm{CHO}$ from the HOPG surface, calculated with the pre-exponential factor $A=10^{18} \mathrm{~s}^{-1}$ are shown. Bottom panel: the surface population (ML) of $\mathrm{NH}_{2} \mathrm{CHO}$ on HOPG surface as a function of the desorption energy (K) is shown. The desorption energy distribution $\left(E_{i}\right)$ and the surface population $\left(N_{i}\right)$ of formamide are derived from Eq. (5) with the best pre-exponential factor $A=10^{18} \mathrm{~s}^{-1}$ for the exposure dose $N=\sum_{i=1}^{n} N_{i}=1 \mathrm{ML}$.

(HOPG) and non-porous ASW ice surfaces in the sub-monolayer and monolayer regimes. The desorption energy distributions, $E_{\text {des,dist }}$, of formamide and methylamine are obtained with different pre-exponential factors: $A=10^{18} \mathrm{~s}^{-1}$ for formamide and $A=10^{12} \mathrm{~s}^{-1}$ for methylamine. In the case of formamide $\left(\mathrm{NH}_{2} \mathrm{CHO}\right)$, the decrease in the pre-exponential factor $A$ from $10^{18}$ to $10^{12} \mathrm{~s}^{-1}$, affects the quality of the TPD fits, and reduces the value of the desorption energy of the molecules by $30 \%$. As already mentioned, $A$ and $E_{\mathrm{des}}$ are degenerated parameters that can be derived from a desorption flux at a given temperature $T$. However, the dynamic of desorption gives more constraints on the couple of parameters. Experimentalists seeks for getting the best fit from their experiments, and as evidence, the best fit is obtained with extreme differences in the pre-exponential factor values $\left(A=10^{18}\right.$ and $\left.A=10^{12} \mathrm{~s}^{-1}\right)$ for two apparently similar molecules. The degeneracy of $A$ and $E_{\mathrm{des}}$ has been 


\section{Methylamine on graphite}
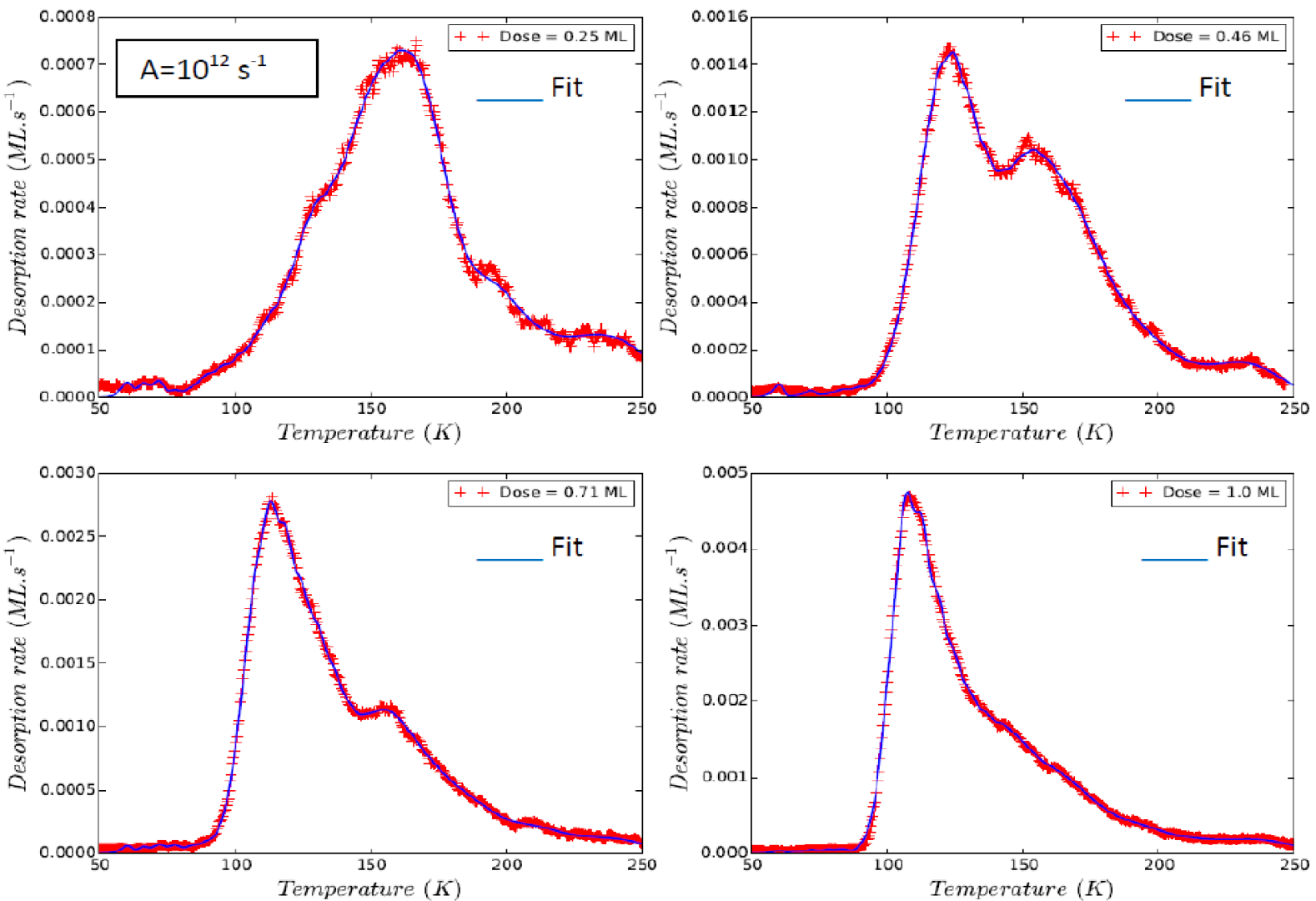

Fig. 6. Modelling results of the desorption rates $\left(\mathrm{ML} \mathrm{s}^{-1}\right)$ of methylamine on graphite (HOPG) surface. $\mathrm{Red} \mathrm{crosses}^{\mathrm{TPD}} \mathrm{Tata}$ of $\mathrm{CH}_{3} \mathrm{NH}_{2}$ $(m / z=31)$ on HOPG surface for different exposure doses of $0.25,0.46,0.71$, and 1.0 ML are shown; blue lines: the best fits of the TPD curves of $\mathrm{CH}_{3} \mathrm{NH}_{2}$ from the HOPG surface, calculated with the best pre-exponential factor $A=10^{12} \mathrm{~s}^{-1}$ are represented.

already estimated and discussed previously. Simple molecules (like $\mathrm{H}_{2}$ ) seems to have a pre-exponential factor for desorption usually close to $10^{12-13} \mathrm{~s}^{-1}$ (Amiaud et al. 2006). On the contrary, Doronin et al. (2015) have shown that the same molecule $\left(\mathrm{CH}_{3} \mathrm{OH}\right)$ could have different pre-exponential factors for different substrates or regimes (multi-layers or sub-monolayer). These authors proposed a method to derive the pre-exponential factor from TPD data. It has been suggested by Tait et al. (2005) that the pre-exponential factor $A$ for the desorption depends on the potential interaction of the adsorbate substrate system, and the number of degrees of freedom of the molecule when it passes from the adsorbate state to the gas-phase transition state. These authors have demonstrated the increase of the pre-factor $A$ for desorption with the chain length of the molecule from the value $10^{13}$ to $10^{19} \mathrm{~s}^{-1}$, and have explained this variation of $A$ by the increase in the rotational entropy available to the molecules in the gas-like transition state for desorption. The difference in the preexponential factor values is an experimental fact. In this work, we want to determine the binding energy distributions of molecules, and once done, we need to be able to compare the different values, originating from different works or analysis methods.

Table 1 shows the maximum of the desorption energies $\left(E_{\mathrm{des}, \max }\right)$ of formamide and methylamine from different substrates, calculated from the model, with the original suitable preexponential factors $(A)$, and with a fixed value $\left(A=10^{12} \mathrm{~s}^{-1}\right)$ for better comparison with other relevant astrophysical molecules, using the following desorbing flux relationship:

$r(T)=A_{1} \mathrm{e}^{-E_{1, \text { des }} / k_{\mathrm{B}} T}=A_{2} \mathrm{e}^{-E_{2, \text { des }} / k_{\mathrm{B}} T}$, where $A_{1}$ and $A_{2}$ are the pre-exponential factors $\left(\mathrm{s}^{-1}\right)$, associated with the desorption energies $E_{1 \text {,des }}$ and $E_{2 \text {,des }}$, respectively, of the adsorbed molecules on the surface, and $T$ is the experimental temperature $(\mathrm{K})$ of the surface, at which the desorption is observed.

In Table 1, we can compare the value of the binding energy of methanol $\left(\mathrm{CH}_{3} \mathrm{OH}\right)$ on graphite with those of methylamine and formamide. We can see that even though the pre-exponential factors and analysis methods are different, all the approximated values of binding energies given here are close and can be compared to the value of the binding energy of the amorphous water ice derived from the same calculation method. The important result here is that, in any case, the binding energy of $\mathrm{CH}_{3} \mathrm{OH}$ is lower than that of water. Table 1 also shows that for the same employed pre-exponential factor $A=10^{12} \mathrm{~s}^{-1}$, the maximum of the desorption energy distribution $\left(E_{\mathrm{des}, \max }=5265 \mathrm{~K}\right)$ of $\mathrm{NH}_{2} \mathrm{CHO}$ from graphite (HOPG) substrate is smaller than the value $(6871 \mathrm{~K})$ of the mean desorption energy obtained from silicate $\left(\mathrm{SiO}_{2}\right)$ interstellar grain analogue surface by Dawley et al. (2014). This difference between our result and that of Dawley et al. (2014) is an indication that the desorption energy of formamide depends on the substrate itself.

More precisely, we find that the binding energy of $0.1 \mathrm{ML}$ of formamide adsorbed on graphite substrate is 5600-5900 K, calculated with $A=10^{12} \mathrm{~s}^{-1}$. These values are smaller than the value given on silicate substrate (Dawley et al. 2014). This difference may not be only related to the composition of the substrate (silicate, graphite), but could also be due to the difference in the morphology of the substrate, which can easily change the 

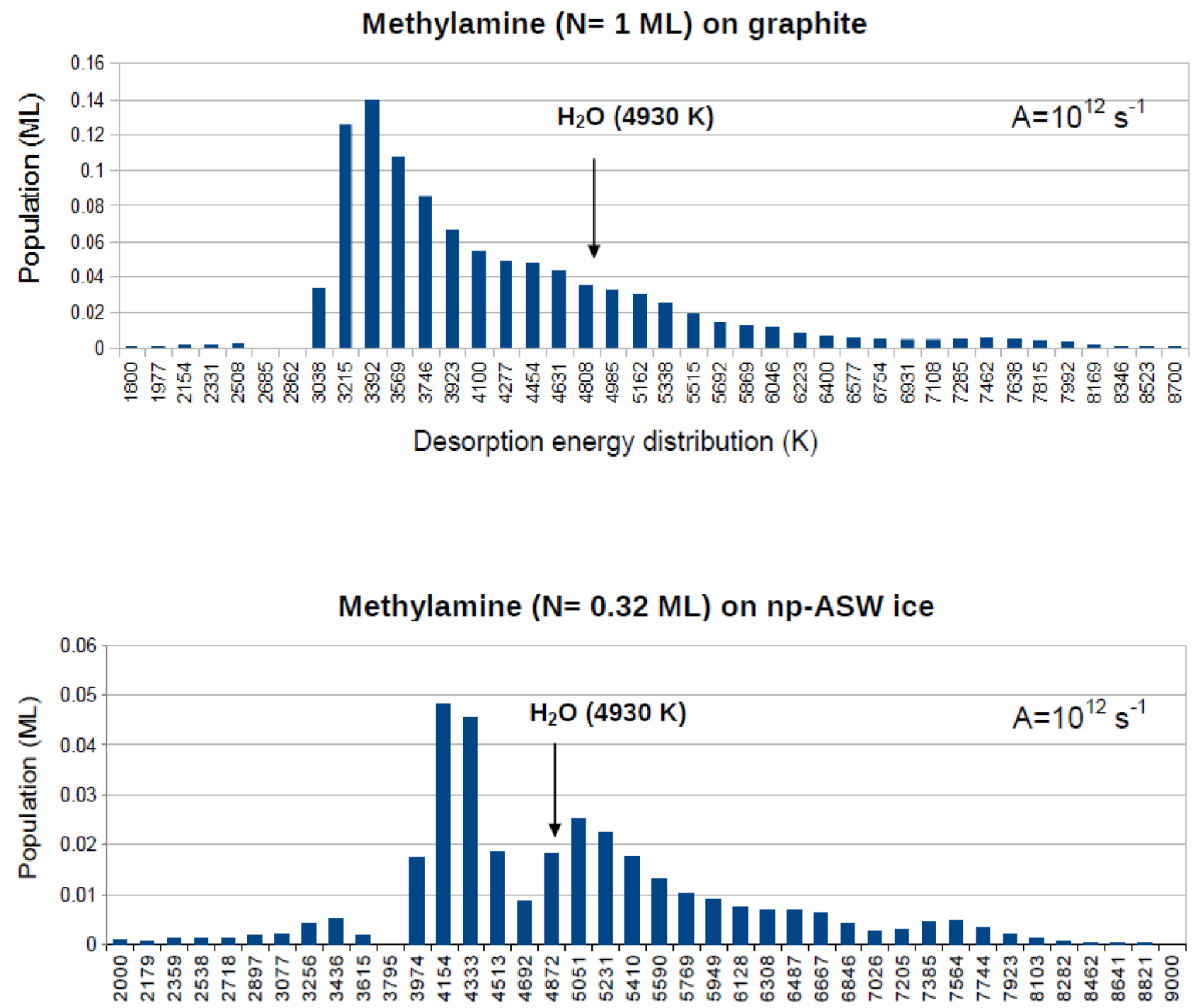

Desorption energy distribution $(\mathrm{K})$

Fig. 7. Modelling results of the desorption energy distributions (K) of methylamine on graphite (HOPG) and np-ASW ice surfaces. Top panel: surface population (ML) of $\mathrm{CH}_{3} \mathrm{NH}_{2}(\mathrm{~m} / z=31)$ as a function of the desorption energy (K) for an exposure dose $N=1 \mathrm{ML}^{\mathrm{N}} \mathrm{CH}_{3} \mathrm{NH}_{2}$ on the HOPG surface. Bottom panel: surface population (ML) of $\mathrm{NH}_{2} \mathrm{CH}_{3}$ as a function of the desorption energy (K) for an exposure dose $N=0.30 \mathrm{ML}$ of $\mathrm{CH}_{3} \mathrm{NH}_{2}$ on the surface of the np-ASW ice film of $10 \mathrm{ML}$ thickness, prepared at $110 \mathrm{~K}$ and cooled down to $40 \mathrm{~K}$. The desorption energy distribution $\left(E_{i}\right)$ and the surface population $\left(N_{i}\right)$ of methylamine are derived from Eq. (5) with the best pre-exponential factor $A=10^{12} \mathrm{~s}^{-1}$ for the two exposure doses $N=\sum_{i=1}^{n} N_{i}=1 \mathrm{ML}$ on HOPG and $N=\sum_{i=1}^{n} N_{i}=0.30 \mathrm{ML}$ on np-ASW ice surfaces.

binding energy distribution of the molecules by a few tens of percent (Fillion et al. 2009). In our experiments, the desorption energy of formamide from the surface of the non-porous ASW ice cannot be measured because the water substrate desorbs before formamide, that is deposited on top of it. Actually, the whole binding energy distribution of formamide from graphite (5056-6990 K), calculated with $A=10^{12} \mathrm{~s}^{-1}$ for $1 \mathrm{ML}$ coverage, is higher than the binding energy values of water ice in its amorphous (4810 K), and crystalline state (4930 K). Unlike formamide, solid methylamine can desorb under different forms, in the multi-layer regime $\left(\mathrm{NH}_{2} \mathrm{CH}_{3}-\mathrm{NH}_{2} \mathrm{CH}_{3}\right)$ with low desorption energies (3010-3490 K) from the np-ASW ice surface with desorption energies (3900-4500 K) and even later from the HOPG substrate with higher desorption energies (5050-8420 K). The different desorption energies of methylamine calculated in this work with respect to that of pure amorphous water ice $(4810 \mathrm{~K})$ is due to its wetting ability compared to $\mathrm{H}_{2} \mathrm{O}$ molecules. In fact, $\mathrm{CH}_{3} \mathrm{NH}_{2}$ species are able to spread readily and uniformly over the surface of the graphite (HOPG) or the amorphous water ice by hydrogen bonds, thereby forming a thin and continuous film in which physisorbed molecules populate a large distribution of surface binding sites. The proportion of molecules desorbing, prior, during, or after the water ice varies with the doses of methylamine, but each time the fraction of methylamine desorbing after the water ice is about $0.15 \mathrm{ML}$. However, the fraction of methylamine co-desorbing with the crystalline phase of the water ice is very small at about $0.03 \mathrm{ML}$. We can see in Fig. 4 that the desorption of methylamine is very reduced during the desorption of the water ice at around $150 \mathrm{~K}$. The desorption of methylamine at $137 \mathrm{~K}$, before the sublimation of the water ice, is delayed compared with its desorption without water at $T=$ $106 \mathrm{~K}$ (Fig. 4), indicating a stronger interaction of methylamine with the water molecule than with itself. In most astrophysical models, the whole desorption of each molecule is described by its (unique) binding energy. For methylamine, the main question is which binding energy shall we propose. Usually, binding 
Table 1. Desorption energy distributions $\left(E_{\text {des,dist }}\right)(\mathrm{K})$, Col. 3, of $\mathrm{NH}_{2} \mathrm{CHO}$ and $\mathrm{CH}_{3} \mathrm{NH}_{2}$ obtained in this work with the best-fit pre-exponential factor $A$ values, expressed $\left(\mathrm{s}^{-1}\right)$.

\begin{tabular}{cccccc}
\hline \hline Molecule & Substrate & $E_{\text {des,dist }}(\mathrm{A})$ & $E_{\text {des,max }}(\mathrm{A})$ & $\begin{array}{c}E_{\text {des,max }} \\
\left(A=10^{12} \mathrm{~s}^{-1}\right)\end{array}$ & References \\
\cline { 3 - 5 } & & $\mathrm{K}\left(\mathrm{s}^{-1}\right)$ & $\mathrm{K}\left(\mathrm{s}^{-1}\right)$ & $\mathrm{K}$ & \\
\hline $\mathrm{NH}_{2} \mathrm{CHO}$ & $\mathrm{HOPG}$ & $7460-9380\left(10^{18}\right)$ & $7700\left(10^{18}\right)$ & 5265 & This work \\
$\mathrm{NH}_{2} \mathrm{CHO}$ & $\mathrm{H}_{2} \mathrm{O}$ & & & $E_{\text {des,dist }}=5056-6990$ & This work \\
$\mathrm{NH}_{2} \mathrm{CHO}$ & $\mathrm{SiO}_{2}$ & & $7397\left(10^{13}\right)$ & 6871 & Dawley et al. (2014) \\
\hline $\mathrm{CH}_{3} \mathrm{NH}_{2}$ & $\mathrm{NH}_{2} \mathrm{CH}_{3}$ & $3010-3490\left(10^{12}\right)$ & $3307\left(10^{12}\right)$ & 3307 & This work \\
$\mathrm{CH}_{3} \mathrm{NH}_{2}$ & $\mathrm{H}_{2} \mathrm{O}$ & $3900-4500\left(10^{12}\right)$ & $4269\left(10^{12}\right)$ & 4269 & This work \\
$\mathrm{CH}_{3} \mathrm{NH}_{2}$ & $\mathrm{HOPG}$ & $5050-8420\left(10^{12}\right)$ & $5100\left(10^{12}\right)$ & 5100 & This work \\
\hline $\mathrm{NH}_{2} \mathrm{OH}$ & $\mathrm{Silicate}$ & & $6518\left(10^{13}\right)$ & 6080 & Congiu et al. (2012) \\
\hline $\mathrm{CH}_{3} \mathrm{OH}$ & $\mathrm{CH} \mathrm{H}_{3} \mathrm{OH}$ & & $4989\left(5 \times 10^{14}\right)$ & 4169 & Doronin et al. (2015) \\
$\mathrm{CH}_{3} \mathrm{OH}$ & $\mathrm{H}_{2} \mathrm{O}$ & & $4366\left(2 \times 10^{12}\right)$ & 4310 & Martín-Doménech et al. (2014) \\
$\mathrm{CH}_{3} \mathrm{OH}$ & $\mathrm{Graphite}$ & & $5454\left(10^{16}\right)$ & 4257 & Doronin et al. (2015) \\
\hline $\mathrm{H}_{2} \mathrm{CO}$ & $\mathrm{H}_{2} \mathrm{O}$ & $3247\left(10^{13}\right)$ & 2899 & Noble et al. (2012) \\
$\mathrm{H}_{2} \mathrm{CO}$ & $\mathrm{Silicate}$ & $3729\left(10^{13}\right)$ & 3040 & Noble et al. (2012) \\
\hline $\mathrm{H}_{2} \mathrm{O}$ & & & & \\
$\mathrm{Amorphous}$ & $\mathrm{Au}$ & $5600\left(10^{15}\right)$ & 4810 & Fraser et al. (2001) \\
$\mathrm{Crystalline}$ & $\mathrm{Au}$ & $5773\left(10^{15}\right)$ & 4930 & Fraser et al. (2001) \\
\hline
\end{tabular}

Notes. Col. 4 gives the maximum of the desorption energy $\left(E_{\text {des,max }}\right)(\mathrm{K})$ obtained with the best-fit pre-exponential factor $A$ values $\left(\mathrm{s}^{-1}\right)$ for $\mathrm{NH}_{2} \mathrm{CHO}, \mathrm{NH}_{2} \mathrm{CH}_{3}$, and other astrophysical relevant molecules $\left(\mathrm{NH}_{2} \mathrm{OH}, \mathrm{CH}_{3} \mathrm{OH}, \mathrm{H}_{2} \mathrm{CO}\right.$, and $\left.\mathrm{H}_{2} \mathrm{O}\right)$ taken from the literature. For a comparison, Col. 5 gives the desorption energies $\left(E_{\text {des,max }}\right)$ of all the molecules calculated with the typical pre-exponential factor $A=10^{12} \mathrm{~s}^{-1}$ for various grain surfaces, using Eq. (7) of flux desorption $\left(A_{1} \mathrm{e}^{-E_{1, \text { des }} / k_{\mathrm{B}} T}=A_{2} \mathrm{e}^{-E_{2, \text { des }} / k_{\mathrm{B}} T}\right)$, and the values of $A$ and $E_{\text {des,max }}$ in Col. 4.

energies are measured for pure species and therefore, the answer would be $E_{\mathrm{des}} \simeq 3000 \mathrm{~K}$ with $A=10^{12} \mathrm{~s}^{-1}$. But in an astrophysical context, the proportion of methylamine in icy mantles is certainly less than a few $\%$ as it is not positively detected in ices (Boogert et al. 2015). Therefore, it would be better to take the low concentration limit of our experiments $(\sim 0.15 \mathrm{ML})$, which would lead to an estimation of the binding energy at around $6000 \mathrm{~K}$, well above the value of those of the water ice. This low coverage value is certainly very dependent on the substrate and represents the wetting properties of the surface for a specific molecule. This is probably why Souda (2016) did not find a late desorption of methylamine in the case of metallic surface $\mathrm{Ni}(111)$. The key question is to find out whether at low concentration, the binding energy of a specific molecule is higher than the binding energy of the water ice. Table 1 reveals that the binding energies of methanol $\left(\mathrm{CH}_{3} \mathrm{OH}\right)$ and formaldehyde $\left(\mathrm{H}_{2} \mathrm{CO}\right)$ are lower than that of amorphous $\left(\mathrm{H}_{2} \mathrm{O}\right)$ water ice, and so we can consider these molecules as volatile, or at least they would desorb with the water ice mantle. For some other molecules, such as $\mathrm{NH}_{2} \mathrm{OH}$ and $\mathrm{NH}_{2} \mathrm{CHO}$, the binding energy is higher than that of $\left(\mathrm{H}_{2} \mathrm{O}\right)$ water ice, and we can consider these molecules as refractory species, compared to water molecules. Refractory does not have the same meaning here as sometimes used in shock-regions studies or in geology. Here, it is the remaining part of the molecular mantle after the sublimation of water. Before this study, we were wondering if some simple chemical properties could explain the common trends of the binding energies. It is usually discussed in terms of hydrophilic and hydrophobic proprieties of the molecules or in terms of hydrogen bonding formation with water. We can sort molecules in two groups: those with a binding energy less than that of water, such as $\mathrm{CH}_{3} \mathrm{OH}, \mathrm{NH}_{3}$, $\mathrm{H}_{2} \mathrm{CO}$, and another group with a binding energy, at low coverage, that are higher than the binding energy of water, among which we can find $\mathrm{H}_{2} \mathrm{O}_{2}$ (Dulieu et al. 2017), $\mathrm{NH}_{2} \mathrm{OH}$ (Congiu et al. 2012), and $\mathrm{NH}_{2} \mathrm{CHO}$. As a matter of fact, the hydrophobic nature of the methyl $\left(-\mathrm{CH}_{3}\right)$ group, or the hydrophilic nature of the amino $\left(-\mathrm{NH}_{2}\right)$ or hydroxyl $(-\mathrm{OH})$ groups, cannot explain our observations. Only detailed calculations could probably give a real understanding of this empirical sorting.

Formamide and methylamine that diffuse completely or partly through the ASW ice surface towards the graphitic substrate and desorb into the gas phase at higher temperatures $(\geq 160 \mathrm{~K})$ are considered as refractory species, which can remain frozen on dust grains even after water ice sublimation. This result leads us to consider different scenarios, in which formamide and methylamine can be formed either in the gas phase and then accreted onto the ice surface or formed by grain-surface chemistry. In the case of the gas-phase formation, the diffusion of the adsorbed molecules on the colder ice mantle at $10-20 \mathrm{~K}$ is an open question, since it depends on the thickness, porosity, and chemical composition of the ice mantle (Mispelaer et al. 2013; Lauck et al. 2015). In the case of grain-surface chemistry, $\mathrm{NH}_{2} \mathrm{CHO}$ and $\mathrm{CH}_{3} \mathrm{NH}_{2}$ molecules may be formed on icy grain mantles in the interstellar medium, by exothermic reactions between mobile radicals, generated by ultraviolet (UV) radiation, or trapped within the bulk of ice mantles of dust grains (Taquet et al. 2012), probably at 30-40 K, once the protostar starts heating its immediate surroundings, as has been suggested by grain surface chemistry models of Garrod \& Herbst (2006). The diffusion of the molecules within the water ice 
to the surface of dust grains by hydrogen bonding formation depends on the morphology of the ices (Lauck et al. 2015) and mainly on the surface of the dust grain below the water ice. The diffusion of $\mathrm{NH}_{2} \mathrm{CHO}$ molecule from the water ice surface to the graphitic substrate is possibly favoured by the formation of larger groups of segregated $\mathrm{NH}_{2} \mathrm{CHO}$ molecules, which bind together by intermolecular van der Waals interactions, and with $\mathrm{H}_{2} \mathrm{O}$ molecules by hydrogen bonds through the amino $\left(-\mathrm{NH}_{2}\right)$ and carbonyl $(-\mathrm{C}=\mathrm{O})$ functional groups. The fast diffusion of $\mathrm{NH}_{2} \mathrm{CHO}$ molecules through the water ice may occur during the reorganization of the ices, and the transition phase from the amorphous to the crystalline structure of the ASW ice at about 145 K (Mispelaer et al. 2013; Dawley et al. 2014). In the interstellar medium, dust grains can be composed of relevant astrophysical materials, such as amorphous carbon (a-C), amorphous silicon (a-Si), and amorphous silicates $\left(\mathrm{Mg}_{2} \mathrm{SiO}_{4}\right.$ and $\mathrm{Fe}_{2} \mathrm{SiO}_{4}$ ). Amorphous carbon (a-C), such as a diamond, has been shown to consist of graphitic islands, composed of compact polycyclic aromatic ring structures, poorly connected with each other Duley et al. (1989). These astrophysical relevant surfaces, characterized by deepest binding sites and highest binding energies, in comparison to the surface of the amorphous water ices, may affect the diffusion proprieties of the molecules. So methylamine and formamide molecules interact strongly with these amorphous carbon and silicon surfaces after water ice evaporation. Formamide molecules are expected to fully diffuse from the water ice surface to these interstellar analogue surfaces.

If dust grains are heated, as in the case of those located nearby a newly born protostar, the external heat provided by the protostars increases the surface temperature of the ice mantle, provoking desorption from the ice back to the gas phase of the volatile molecules, such as $\mathrm{CO}, \mathrm{CO}_{2}$, and $\mathrm{H}_{2} \mathrm{O}$ or $\mathrm{CH}_{3} \mathrm{OH}$. As the thickness of the water ice on the dust grain is reduced, the non-volatile formamide molecules diffuses through the water ice and populates the highest bindings sites of dust grains. Therefore the presence in the gas phase of refractory molecules, if these molecules come from the solid phase, would require a higher final temperature of dust grains. These refractory molecules should be observed on a separate snow line. Furthermore, this thermal desorption should be accompanied by a blending of the species and some induced reactivity, as described in for example Theulé et al. (2013), Dulieu et al. (2017), and in Souda (2016) for the H-D exchange in ices. But the presence of molecules in the gas phase coming from the solid phase can arise from the sputtering of the grain mantle, especially in shocks (e.g. Draine 1983; Jones et al. 1994; Tielens et al. 1994). This type of desorption process is not at thermal equilibrium, but is induced by gaseous bombardment with an energy greater than the surface binding energies, provoking the ejection of the material in gas environments. This kind of ballistic kick out mechanism should be sensitive to the binding energy of the molecules.

Recent astronomical observations of Bacmann et al. (2012) have suggested that complex organic molecules (COMs) are actively formed in prestellar cores in L1689B before the gravitational collapsing phase leading to protostar formation and even before the warm-up phase of the grains. Many COMs have been detected in cold dark prestellar cores at low temperature $(T \sim 10 \mathrm{~K})$. This includes dimethyl ether $\left(\mathrm{CH}_{3} \mathrm{OCH}_{3}\right)$, methyl formate $\left(\mathrm{CH}_{3} \mathrm{OCHO}\right)$, acetaldehyde $\left(\mathrm{CH}_{3} \mathrm{CHO}\right)$, ketene $\left(\mathrm{CH}_{2} \mathrm{CO}\right)$, cyclopropenone $\left(\mathrm{c}-\mathrm{C}_{3} \mathrm{H}_{2} \mathrm{O}\right)$, propynal (HCCCHO), vinyl cyanide $\left(\mathrm{CH}_{2} \mathrm{CHCN}\right)$, and propyne $\left(\mathrm{CH}_{3} \mathrm{CCH}\right)$ (JiménezSerra et al. 2016; Vastel et al. 2014; Bacmann et al. 2012). Here one of the main efficient mechanism included in astrochemical models to feed back the gas phase is the impulsive heating of dust grains by $\mathrm{X}$-rays and cosmic rays, already proposed earlier by Leger et al. (1985). Here again, the binding energy of the molecules is still a selective parameter because it explicitly enters in the calculation of the desorption of each type of molecules. Although this is not exactly the same mechanism than found in thermal desorption, in practice, models sort molecules depending on their binding energies. Therefore, in the context of prestellar cores, a very high binding energy also prevents any return in the gas phase. The second efficient mechanism for populating the gas phase is the chemical desorption (or reactive desorption) (Takahashi \& Williams 2000; Garrod et al. 2007; Dulieu et al. 2013). Here, the energy released during the formation of the molecule itself is the promoter of the desorption. But the probability of desorption has been proposed to decrease exponentially with the binding energy, among others factors (Minissale et al. 2016). The COMs detected in cold dark prestellar cores regions are likely to originate from gas-phase reactions at $10-20 \mathrm{~K}$ of precursor molecules, such as formaldehyde and methanol, which are previously formed on icy grain surfaces, then ejected into the gas phase by desorption induced by chemical reaction, and finally followed by gas-phase chemistry via ion molecules (Vasyunin \& Herbst 2013), neutral-neutral, and radiative association reactions (Vasyunin et al. 2017). These molecules detectable in the gas phase can in turn be involved in gas-phase reactions to form more complex organic molecules. It is therefore, interesting to explore the interaction of these detected COMs with the ASW ice and with various astrophysical relevant substrates. Formamide and methylamine are probably forming in regions where $\mathrm{CO}$ has also started to freeze-out, i.e. in dense molecular clouds. In these regions, the icy mantle might be composed of water ice in the presence of $\mathrm{CO}$ molecules or a mixture of $\mathrm{CO}_{2}$ and $\mathrm{H}_{2} \mathrm{O}$ ices. However, since $\mathrm{CO}$ desorbs at 30$50 \mathrm{~K}$ from the amorphous water ice surface (Noble et al. 2012), it is probably that its presence with $\mathrm{H}_{2} \mathrm{O}$ molecules does not affect the diffusion of formamide and methylamine from the water ice surface towards the substrate, such as graphite HOPG, at the expected temperatures of 110-140 K. Nevertheless, it would be interesting to perform further adsorption-desorption laboratory experiments of formamide and methylamine on mixed or layered $\mathrm{CO}, \mathrm{CO}_{2}$, and $\mathrm{H}_{2} \mathrm{O}$ ices to understand the effect of this relevant astrophysical molecule on the diffusion process of the complex organic molecules through the ASW ice. It would also be interesting to explore other substrates, such as amorphous silicon (a-Si) and amorphous carbon (a-C), which better represent the interstellar dust grains composition than HOPG to study the effect of the substrate on the desorption energies and the diffusion of these two molecules, and other COMs from the water ice surfaces.

\section{Conclusions}

The desorption of formamide $\mathrm{NH}_{2} \mathrm{CHO}$ and methylamine $\mathrm{CH}_{3} \mathrm{NH}_{2}$ molecules has been investigated experimentally on graphite (HOPG) and np-ASW water ice surfaces in the submonolayer and monolayer regimes, using the TPD technique.

Experimental results show an efficient diffusion of more than $95 \%$ of formamide through the np-ASW ice film of $10 \mathrm{ML}$ thickness towards the graphite (HOPG) substrate. The large percentage of solid formamide ( $>0.95 \mathrm{ML}$ ) bound to the graphitic substrate desorbs at higher surface temperature, $176 \mathrm{~K}$, whatever the surface coverage, after the desorption of the water ice 
at about $150 \mathrm{~K}$. The diffusion of $\mathrm{NH}_{2} \mathrm{CHO}$ is likely to occur during the warming-up phase of the ices at a short timescale of few seconds.

$\mathrm{CH}_{3} \mathrm{NH}_{2}$ molecules physisorbed on the ASW ice desorbs at $137 \mathrm{~K}$, before the desorption of the $\mathrm{H}_{2} \mathrm{O}$ molecules at $150 \mathrm{~K}$, and even from the energetic sites of the HOPG surface at higher temperatures 160-220 K. Because of the wetting ability of the methylamine compared to water, the fraction of solid methylamine that diffuses through the water ice surface towards the graphitic substrate is about 0.15 ML. The amounts of formamide and methylamine desorbing from the graphite dust grains after water ice sublimation are considered as refractory species, which can enrich the gas phase of warm interstellar environments.

We analysed the binding energy distributions and proposed a convenient way to compare the binding energies directly, by comparing these energies with an arbitrary fixed pre-exponential factor $\left(A=10^{12} \mathrm{~s}^{-1}\right)$. The main difference in behaviour of these two molecules is probably because the entire binding energy distribution of formamide $\left(E_{\mathrm{des}}=5056-6990 \mathrm{~K}\right)$ is higher than the value of the amorphous water desorption $\left(E_{\mathrm{des}}=4810 \mathrm{~K}\right)$. On the contrary, the binding energy distribution of methylamine $\left(E_{\mathrm{des}}=3010-8420 \mathrm{~K}\right)$ is distributed over this value. There is no obvious link between the chemical functional groups (amino, hydroxyl, methyl, and carbonyl) and the binding energy distribution on our graphite template. The simple idea that all the molecules should desorb during the sublimation of the ice mantle is certainly unrealistic and illusive. The difference in the binding energies of formamide and methylamine could have an impact on the composition of the gas-phase environments, in particular in the coma of comets, but also in hot cores, hot corinos, and protoplanetary disks.

Acknowledgements. This work was supported by the Programme National "Physique et Chimie du Milieu Interstellaire (PCMI)" of CNRS/INSU with INC/INP co-funded by CEA and CNES. H.C would like to thank Prof. Darek Lis, Prof. Jean-Hugues Fillion of the LERMA team for their support and helpful corrections. The authors acknowledge the anonymous referee for constructive comments that greatly improved the paper. T.N. is granted by the LabEx MICHEM. Formamide is a target molecule of SOLIS, a NOEMA key programme led by C. Ceccarelli and P. Caselli.

\section{References}

Altwegg, K., Balsiger, H., Bar-Nun, A. et al. 2016, Sci. Adv., 2, 1

Amiaud, L., Dulieu, F., Baouche, S., et al. 2006, in Astrochemistry - From Laboratory Studies to Astronomical Observations, eds. R. I. Kaiser, P. Bernath Y. Osamura, S. Petrie, \& A. M. Mebel, Am. Inst. Phys. Conf. Ser., 855, 55

Amiaud, L., Dulieu, F., Fillion, J.-H., Momeni, A., \& Lemaire, J. L. 2007, J. Chem. Phys., 127, 144709

Bacmann, A., Taquet, V., Faure, A., Kahane, C., \& Ceccarelli, C. 2012, A\&A, 541, L12

Barone, V., Latouche, C., Skouteris, D., et al. 2015, MNRAS, 453, L31

Bernstein, M. P., Sandford, S. A., Allamandola, L. J., Chang, S., \& Scharberg, M. A. 1995, ApJ, 454, 327

Bhushan, B., Nayak, A., \& Kamaluddin 2016, Origins of Life and Evolution of the Biosphere, 46, 203
Bisschop, S. E., Jørgensen, J. K., van Dishoeck, E. F., \& de Wachter, E. B. M. 2007, A\&A, 465, 913

Biver, N., Bockelée-Morvan, D., Debout, V., et al. 2014, A\&A, 566, L5

Bockelée-Morvan, D., Lis, D. C., Wink, J. E., et al. 2000, A\&A, 353, 1101

Boogert, A. C. A., Gerakines, P. A., \& Whittet, D. C. B. 2015, ARA\&A, 53, 541

Chaabouni, H., Minissale, M., Manicò, G., et al. 2012, J. Chem. Phys., 137, 234706

Codella, C., Ceccarelli, C., \& Caselli, E. A. 2017, A\&A, 605, L3

Congiu, E., Chaabouni, H., Laffon, C., et al. 2012, J. Chem. Phys., 137, 054713

Coutens, A., Jørgensen, J. K., van der Wiel, M. H. D., et al. 2016, A\&A, 590, L6

Dawley, M., Pirim, C., \& Orlando, T. 2014, J. Chem. Phys. A, 118, 1220

Dohnálek, Z., Kimmel, G. A., Joyce, S. A., et al. 2001, J. Phys. Chem. B, 105, 3747

Doronin, M., Bertin, M., Michaut, X., \& Philippe, L. Fillion, J.-H. 2015, J. Chem. Phys., 143, 084703

Draine, B. T. 1983, ApJ, 270, 519

Duley, W. W., \& Williams, D. A. 1993, MNRAS, 260, 37

Duley, W. W., Jones, A. P., \& Williams, D. A. 1989, MNRAS, 236, 709

Dulieu, F., Congiu, E., Noble, J., et al. 2013, Sci. Rep., 3, 1338

Dulieu, F., Minissale, M., \& Bockelée-Morvan, D. 2017, A\&A, 597, A56

Fedoseev, G., Chuang, K.-J., van Dishoeck, E. F., Ioppolo, S., \& Linnartz, H. 2016, MNRAS, 460, 4297

Fillion, J.-H., Amiaud, L., Congiu, E., et al. 2009, Phys. Chem. Chem. Phys., 11, 4344

Fourikis, N., Takagi, K., \& Morimoto, M. 1974, ApJ, 191, L139

Fraser, H. J., Collings, M. P., McCoustra, M. R. S., \& Williams, D. A. 2001 MNRAS, 327, 1165

Garrod, R. T., \& Herbst, E. 2006, A\&A, 457, 927

Garrod, R. T., Wakelam, V., \& Herbst, E. 2007, A\&A, 467, 1103

Garrod, R. T., Widicus Weaver, S. L., \& Herbst, E. 2008, ApJ, 682, 283

Gerakines, P. A., Moore, M. H., \& Hudson, R. L. 2004, ICARUS, 170, 202

Hartquist, T. W., \& Williams, D. A. 1990, MNRAS, 247, 343

Jiménez-Serra, I., Vasyunin, A. I., Caselli, P., et al. 2016, ApJ, 830, L6

Jones, A. P., Tielens, A. G. G. M., Hollenbach, D. J., \& McKee, C. F. 1994, ApJ, 433, 797

Jones, B. M., Bennett, C. J., \& Kaiser, R. I. 2011, ApJ, 734, 78

Kahane, C., Ceccarelli, C., Faure, A., \& Caux, E. 2013, ApJ, 763, L38

Lauck, T., Karssemeijer, L., Shulenberger, K., et al. 2015, ApJ, 801, 118

Leger, A., Jura, M., \& Omont, A. 1985, A\&A, 144, 147

López-Sepulcre, A., Jaber, A. A., Mendoza, E., et al. 2015, MNRAS, 449, 2438

Martín-Doménech, R., Muñoz Caro, G. M., Bueno, J., \& Goesmann, F. 2014, A\&A, 564, A8

Minissale, M., Congiu, E., \& Dulieu, F. 2016, A\&A, 585, A146

Mispelaer, F., Theulé, P., Aouididi, H., et al. 2013, A\&A, 555, A13

Noble, J. A., Congiu, E., Dulieu, F., \& Fraser, H. J. 2012, MNRAS, 421, 768

Noble, J. A., Theule, P., Congiu, E., et al. 2015, A\&A, 576, A91

Nummelin, A., Bergman, P., Hjalmarson, A., et al. 2000, ApJS, 128, 213

Raunier, S., Chiavassa, T., Duvernay, F., et al. 2004, A\&A, 416, 165

Saladino, R., Botta, G., Pino, S., \& Di Lauro, E. 2012, Chem. Soc. Rev., 41, 5526

Skouteris, D., Vazart, F., Ceccarelli, C., et al. 2017, MNRAS, 468, L1

Song, L. \& Kästner, J. 2016, Phys. Chem. Chem. Phys. (Incorp. Faraday Trans.), 18,29278

Souda, R. 2016, Chem. Phys. Lett., 645, 27

Tait, S. L., Dohnálek, Z., Campbell, C. T., \& Kay, B. D. 2005, J. Chem. Phys., 122,164708

Takahashi, J., \& Williams, D. A. 2000, MNRAS, 314, 273

Taquet, V., Ceccarelli, C., \& Kahane, C. 2012, ApJ, 748, L3

Theule, P., Borget, F., Mispelaer, F., et al. 2011, A\&A, 534, A64

Theulé, P., Duvernay, F., Danger, G., et al. 2013, Adv. Space Res., 52, 1567

Tielens, A. G. G. M., McKee, C. F., Seab, C. G., \& Hollenbach, D. J. 1994, ApJ, 431, 321

Vastel, C., Ceccarelli, C., Lefloch, B., \& Bachiller, R. 2014, ApJ, 795, L2

Vasyunin, A. I., \& Herbst, E. 2013, ApJ, 769, 34

Vasyunin, A. I., Caselli, P., Dulieu, F., \& Jiménez-Serra, I. 2017, ApJ, 842, 33

Wakelam, V., Loison, J.-C., Mereau, R., \& Ruaud, M. 2017, Mol. Astrophys., 6, 22 